\title{
Comparison of aerosol size distribution in coastal and oceanic environments
}

\author{
Jolanta Kusmierczyk-Michulec ${ }^{1}$ and Alexander M.J.van Eijk \\ TNO Defense, Safety and Security, PO Box 96864, The Hague, The Netherlands
}

\begin{abstract}
The results of applying the empirical orthogonal functions (EOF) method to decomposition and approximation of aerosol size distributions are presented. A comparison was made for two aerosol data sets, representing coastal and oceanic environments. The first data set includes measurements collected at the Irish Atlantic coast in 1994 and 1995, the second one data collected during the Rough Evaporation Duct (RED) experiment that took place off Oahu, Hawaii in 2001. The main finding is that aerosol size distributions can be represented by a superposition of the mean size distribution and the first eigenvector multiplied by an amplitude function. For the two aerosol data sets the mean size distribution is very similar in the range of small particles sizes (radius $<1 \mu \mathrm{m}$ ) but the main difference appears for larger aerosols (radius $>1 \mu \mathrm{m}$ ). It is also reflected by the spectral shape of the eigenvector. The differences can be related to the type of aerosols present at both locations, and the amplitude function can be associated to meteorological conditions. The amplitude function also indicates the episodes with the maximum/minimum continental influence. The results of this analysis will be used in upgrades of the ANAM model.
\end{abstract}

Keywords: aerosol size distribution, EOF method, fetch, ANAM

\section{INTRODUCTION}

The Empirical Orthogonal Function (EOF) method has been used for years to analyze, e.g., large meteorological data sets $^{1}$ or the variability of water temperature, salinity, density ${ }^{2}$ and sea level ${ }^{3}$. The method has found an application in the analysis of the temporal and spatial variability of the aerosol optical thickness over the Baltic Sea ${ }^{4,5}$.

The EOF method was also successfully applied to decomposition and approximation of aerosol size distribution data collected during two cruises in the Baltic Sea and during a coastal experiment in Lubiatowo (Poland) ${ }^{6}$ in 1994. The authors found that aerosol size distribution can be presented as a superposition of a slowly varying background of dustlike particles and an additional distribution of sea-spray -sized particles multiplied by an amplitude function reflecting the contribution of marine aerosols. The amplitude was found to be dependent on wind speed, wind direction and fetch, where fetch represents the distance from the coast.

The above findings suggest that the EOF method has the potential to identify the relative contributions of various types of aerosols in an air mass. In particular, the method could provide the ratio between the aerosols of marine origin and those originating from the land (this latter category will be referred to 'continental' aerosols). This type of information is of relevance to electro-optical propagation issues. The aerosols scatter and absorb radiation and thereby induce transmission losses. The transmission loss is quantified by the aerosol extinction, which in turn is a function of the number of particles and their refractive index. Since the refractive index of marine (sea spray) particles differs significantly from that of continental aerosols, it is important to know not just the overall concentration of the aerosol, but also its composition.

The Navy Aerosol Model (NAM) ${ }^{7-9}$ is a well-known engineering tool providing a quick and reasonable estimate of the aerosol extinction on the basis of simple meteorological input data. The NAM is available to the community via the USAF MODTRAN code. ${ }^{10}$ The original NAM consists of 3 lognormal distributions, which describe freshly produced

\footnotetext{
${ }^{1}$ Contact information: jolanta.kusmierczyk@tno.nl, phone: +31 7037407 91, fax: +31 703740654
} 
marine aerosols, aged marine aerosols (produced elsewhere and advected to the measurement site) and a background concentration of marine aerosols. To account for non-marine particles, a special lognormal mode representing dust particles was added. The relative importance of the dust mode versus the marine background concentration is governed by a special input parameter known as the air mass parameter (AMP). The lognormal mode parameters are adjusted as function of the meteorological conditions and the resulting aerosol size distribution is converted to aerosol extinction using a Mie algorithm. More details on NAM can be found elsewhere. ${ }^{11}$

Unfortunately, the AMP is ill-defined and the NAM user community has found it difficult to attribute a proper value to the AMP. This inconvenience became more stressing when NAM was used for assessing aerosol extinction in the coastal zone. The aerosol concentration and composition in the coastal zone changes rapidly in space and time and the performance of the NAM is significantly reduced in this environment. ${ }^{12}$. It has been found that the ratio of marine versus continental aerosols depends strongly on fetch, ${ }^{12}$ which suggests that fetch might be an alternative for the AMP. ${ }^{13,14}$

The NAM is presently being upgraded in the Advanced Navy Aerosol Model ${ }^{11}$. One of the efforts in this project is the replacement of AMP by more suitable parameters, i.e., parameters that can more easily be provided by the users. Within the framework of this task, we are exploring mathematical tools to analyse existing aerosol data sets and to get a handle on the relative ratio of marine and continental aerosols in the coastal zone. Therefore, the EOF method was applied to a coastal data set (acquired in 1994 and 1995 off the West Coast of Ireland). For reference purposes, the method was also applied to an oceanic data set (acquired in 2001 off Oahu HI). It was expected that this latter dataset would contain minimal continental influences.

\section{THE AEROSOL DATA SETS}

\subsection{Experimental equipment}

The experimental procedure to record aerosol data was similar in both sites. Aerosol size distributions were measured simultaneously by two classical scattering spectrometer probes (Particle Measuring Systems, CSASP-200 and CSASP$100 \mathrm{HV}$ ), providing a combined range of diameters between 0.21 and $42.5 \mu \mathrm{m}$. The internal data integration time was 1 second, and raw data was stored on disk after an accumulation time of 1 minute. Later, the raw data was reduced by averaging over 10 minute intervals resulting in total 5654 files for RED experiment and 6577 files (2417 for 1994 and 4160 files representing 1995) for the experiment in Ireland. Prior to the experiments, the probes had been calibrated with particles of known sizes.

Local meteorological conditions such as wind speed and direction, air and sea surface temperature, pressure, and relative humidity were measured using standard sensors. The data from these sensors were also averaged over 10 minutes and stored in the aerosol data files. This yielded large spreadsheets of meteorological data and aerosol data allowing for correlations.

\subsection{RED data set}

The Rough Evaporation Duct (RED) experiment took place off Oahu, Hawaii from 26 August to 15 September 2001 and represents one of the few recent "open ocean" datasets that we have at our disposal. It is thus an excellent dataset to establish the marine aerosol behavior without too much continental disturbance.

During the experiment the aerosol counters and meteorological sensors were installed on the FLIP (see Photo 1), an ONR-sponsored platform maintained by Scripps Institute of Oceanography (SIO). The location of the FLIP during the experiment is shown in Fig.1. The aerosol probes at FLIP were mounted at the height of $20 \mathrm{~m}$ and during the measurements the probes were facing into the wind. 


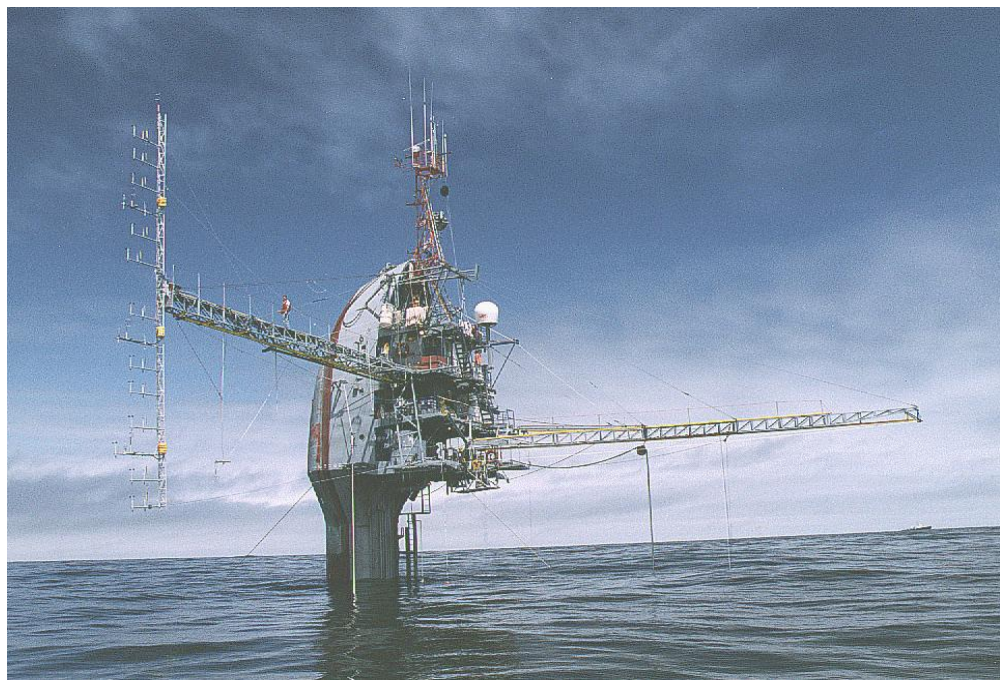

Photo 1. FLIP

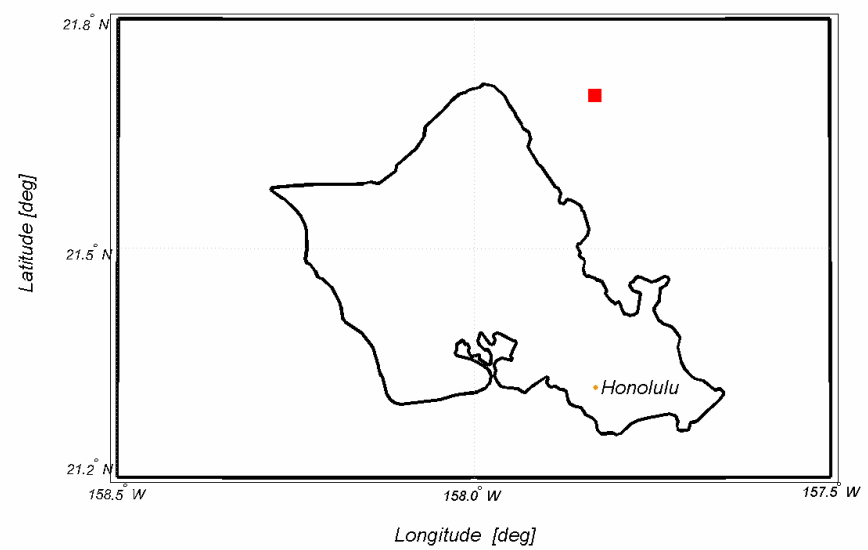

Fig.1. Map of the Oahu Island with the position of FLIP indicated by a square.

\subsection{Inisheer data set}

Particle size distributions and meteorological parameters were measured on the Irish island Inisheer (see Fig.2) during 2 campaigns. One took place from 31 of August to 17 of September 1994 and the second one from 19 of August to 20 of September 1995. To avoid effects due to local surf the aerosol counters and meteorological sensors were placed on the top of the light house, at a height of $30 \mathrm{~m}$. PMS probes were pointed into the open sea direction. The Ireland data set is complimentary to RED because the aerosols collected at Inisheer represent both marine and continental types ${ }^{13}$. 


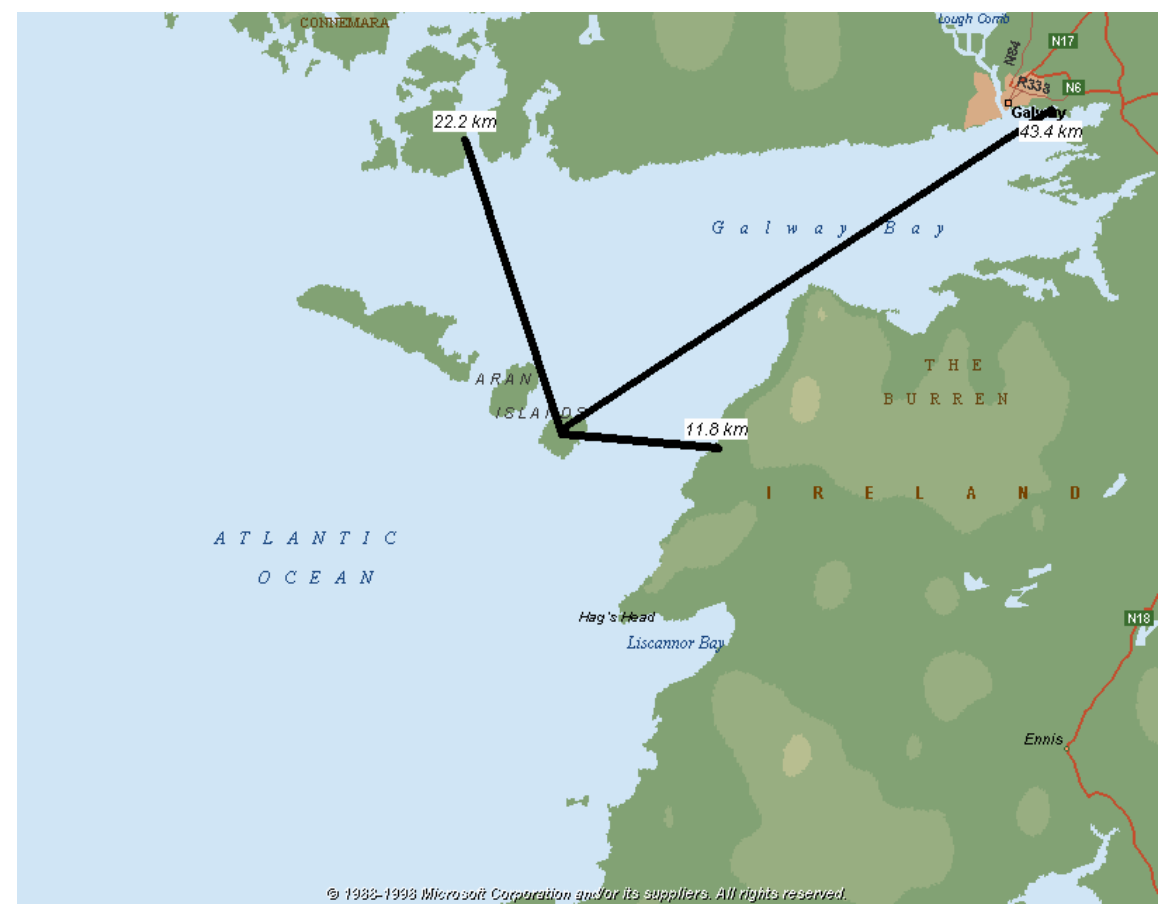

Fig.2. Location of the island Inisheer "at the entrance to the Gulf of Galway". Black lines show three different distances to the coast of the mainland.

\section{DESCRIPTION OF THE EOF METHOD}

Let $\mathrm{n}_{i}\left(\mathrm{~d}_{j}\right)$ be an aerosol size distribution profile, where the subscript $i$ symbolizes each successive measurement, $i=$ $1, \ldots, N$, and the subscript $j$ corresponds to the number of diameter size bins, $j=1, \ldots, M$. The mean aerosol size distribution profile is defined as:

$$
<\mathrm{n}\left(d_{j}\right)>=\frac{1}{N} \sum_{i=1}^{N} \mathrm{n}_{i}\left(\mathrm{~d}_{j}\right) \quad i=1, \ldots, N, \quad j=1, \ldots, M,
$$

and the fluctuations from the mean are given by:

$$
*_{n}\left(d_{j}\right)=\mathrm{n}_{i}\left(d_{j}\right)-<\mathrm{n}\left(d_{j}\right)>\quad i=1, \ldots, N ; \quad j=1, \ldots, M,
$$

The fluctuations are approximated by expanding them into a series of orthogonal functions $h_{k}\left(d_{j}\right)$ :

$$
*_{\mathrm{n}_{i}}\left(d_{j}\right)=\sum_{k=1}^{M} h_{k}\left(d_{j}\right) \beta_{i k} \quad i=1, \ldots, N ; j=1, \ldots, M
$$

where the functions $h_{\mathrm{k}}\left(\mathrm{d}_{\mathrm{j}}\right)$ should fulfill the conditions of orthogonality and be normalized.

$$
\sum_{j=1}^{M} h_{i}\left(d_{j}\right) h_{k}\left(d_{j}\right)=M \delta_{i k}
$$

where $\delta_{i k}=0$ for $i \neq k, 1$ for $i=k$ 
The functions $h_{\mathrm{k}}\left(d_{j}\right)$ are called modes or main components, the coefficients $\beta_{\mathrm{ik}}$ are called amplitude functions or simply amplitudes $^{1,15}$. In the EOF method, functions $h_{\mathrm{k}}$ are chosen as eigenfunctions (eigenvectors) of the covariance matrix $\Im\left(d_{i}, d_{j}\right)$,

$$
\Im\left(\mathrm{d}_{\mathrm{i}}, \mathrm{d}_{\mathrm{j}}\right)=\frac{1}{N} \sum_{k=1}^{N} * \mathrm{n}_{\mathrm{k}}\left(\mathrm{d}_{\mathrm{i}}\right) * \mathrm{n}_{\mathrm{k}}\left(\mathrm{d}_{\mathrm{j}}\right), \quad i, j=1, \ldots, M
$$

which, at the same time, are solutions of

$$
\sum_{i=1}^{M} \Im\left(\mathrm{d}_{i}, \mathrm{~d}_{j}\right) h_{k}\left(\mathrm{~d}_{i}\right)=\wp_{\mathrm{k}} h_{\mathrm{k}}\left(\mathrm{d}_{\mathrm{j}}\right) \quad j, k=1, \ldots, M
$$

where $\wp_{\mathrm{k}}$ are eigenvalues of the covariance matrix. Eigenvalues $\wp_{\mathrm{k}}$ and eigenvectors $h_{\mathrm{k}}$ are calculated by Jacobi's method $^{16}$.

The aerosol size distribution can be thus presented in the following form:

$$
\mathrm{n}_{\mathrm{i}}\left(\mathrm{d}_{\mathrm{j}}\right)=\sum_{k=1}^{L} h_{\mathrm{k}}\left(\mathrm{d}_{\mathrm{j}}\right) \beta_{\mathrm{ik}}+<\mathrm{n}\left(\mathrm{d}_{\mathrm{j}}\right)>\quad i=1, \ldots, N
$$

where $L$ is the number of modes chosen in accordance with the criterion $\mathfrak{R}(L)$, defining the contribution of the eigenvalues to the total variance,

$$
\mathfrak{R}(L)=\sum_{i=1}^{L} \wp_{\mathrm{i}} / \sum_{i=1}^{M} \wp_{\mathrm{i}}
$$

Values of $\mathfrak{R}(L)$ are assumed to be of the order of $0.90-0.95^{2,3}$. Mode $h_{1}$ contains the maximum energy of the entire data set, mode $h_{2}$ contains the maximum energy of what is left after the first mode has been subtracted, etc.

\section{RESULTS}

\subsection{Application of the EOF method}

The following diameters were selected for the vector $\mathrm{j}=1 \ldots M$ to represent the aerosol size distribution: $0.25,0.27,0.3$, $0.4,0.5,0.6,0.7,0.8,0.9,1.0,1.5,2,3,4,5,6,7,8,9,10,11,12,13,14$ and $15 \mu \mathrm{m}$. In case of the Inisheer data set the the concentrations of larger particles were very low and the upper limit of diameters was therefore set to $12 \mu \mathrm{m}$. The EOF method was applied to the RED and Inisheer data sets separately. In both cases the contribution of the first eigen value to the total variance was higher than $98 \%$. Such a large value allows taking into account only the first eigenvector $h_{1}$ and to neglect the remaining modes. Then, all aerosol size distribution profiles can be described by means of one general equation:

$$
\begin{gathered}
\mathrm{n}_{\mathrm{i}}\left(\mathrm{d}_{\mathrm{j}}\right)=h_{1}\left(\mathrm{~d}_{\mathrm{j}}\right) \beta_{\mathrm{i} 1}+<\mathrm{n}\left(\mathrm{d}_{\mathrm{j}}\right)>\quad i=1, \ldots, N, \mathrm{j}=1 \ldots M, \\
\text { or equivalently } \\
\mathrm{n}_{\mathrm{i}}\left(\mathrm{r}_{\mathrm{j}}\right)=h_{1}\left(\mathrm{r}_{\mathrm{j}}\right) \beta_{\mathrm{i} 1}+<\mathrm{n}\left(\mathrm{r}_{\mathrm{j}}\right)>\quad i=1, \ldots, N, \mathrm{j}=1 \ldots M,
\end{gathered}
$$

where $r$ indicates a radius. The added value of the eq.9 is that instead of analyzing the differences between the concentration values at a single diameter we can analyze the differences between the vectors describing the size distribution over the whole range of discrete diameters. 


\subsection{The number size distribution}

The EOF results for both data sets are presented in Figure 3. The profile of the mean number size distribution in the range of small particles sizes (radius $<1 \mu \mathrm{m}$ ) looks very similar for RED and Inisheer data sets. The main difference appears for larger aerosols. It is also illustrated by the first eigenvectors (marked ' $h 1$ ' in the plot).

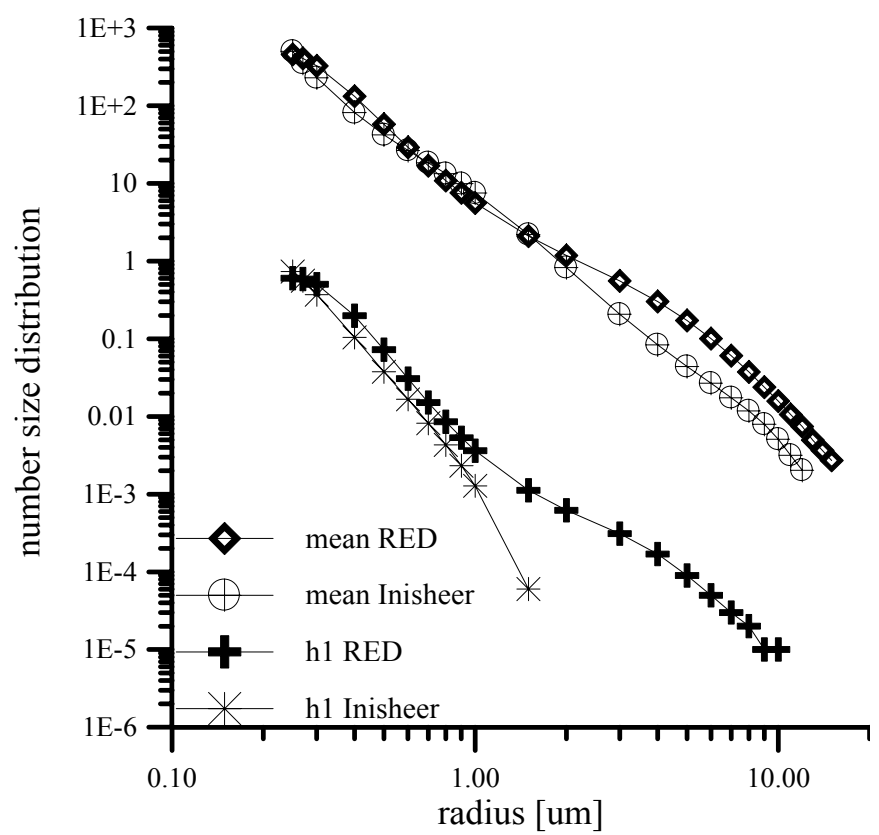

Fig.3. The EOF results i.e. mean distribution $<\mathrm{n}(\mathrm{r})>$ and the first eigenvector h1(r), for the RED and Inisheer data sets.

\subsection{The volume size distribution}

To highlight the differences between the two datasets, the EOF results were converted to volume size distributions. The difference between the two mean volume size distributions, calculated from the mean number size distribution, for dry aerosols, is shown in Figures 4A. The curve for the RED data can be interpreted as the mean volume distribution for oceanic aerosols. Therefore the domination of particles with dry radius $>1 \mu \mathrm{m}$ is understandable. In contrast, the mean volume distribution for the Inisheer data can be regarded as a mixture of continental and maritime aerosols. The peaks of marine (around $3 \mu \mathrm{m}$ ) and continental (around $0.3 \mu \mathrm{m}$ ) are thus more comparable in amplitude. 
A)

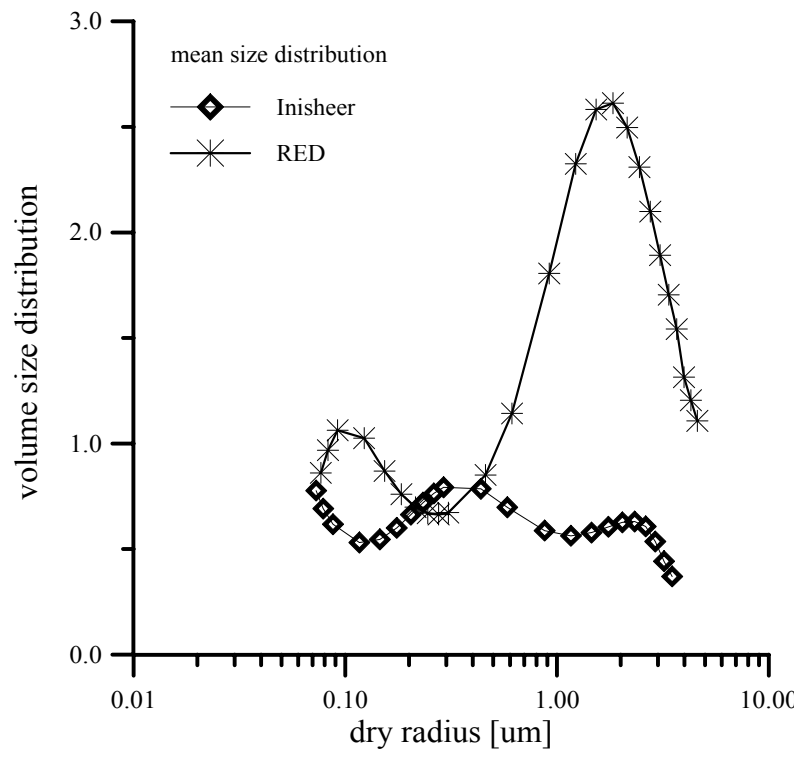

B)

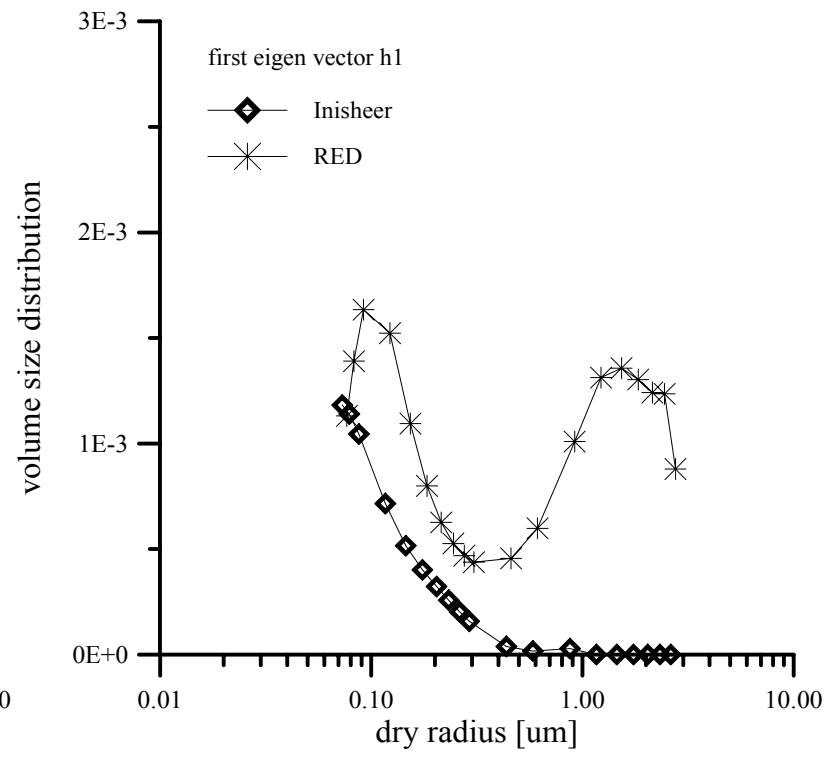

Fig. 4. Volume size distributions for dry aerosols, for RED and Inisheer data, converted from the mean number size distribution (Fig.4A on the left) and distributions representing the first eigenvectors (Fig. $4 \mathrm{~B}$ on the right).

Figure 4B shows the behavior of the first eigenvectors. In case of the Inisheer data the eigenvector can be interpreted as a size distribution of additional continental particles. The amount of its contribution is defined by the amplitude function. In case of the RED data the profile of $\mathrm{h} 1$ suggests that additional particles have bimodal distribution with fine mode related to particles of a continental origin, and with coarse mode related to oceanic particles.

\subsection{The amplitude function}

The amplitude function $\beta_{\mathrm{i} 1}$ can be used as an indicator to the episodes with the maximum/minimum contribution of the first eigenvector. Using the eq.10 the extreme values of the aerosol size distributions can be presented in the following form:

$$
\mathrm{n}_{\max / \min }(\mathrm{r})=h_{1}(\mathrm{r}) \beta_{\max / \min }+<\mathrm{n}(\mathrm{r})>
$$

The amplitude function for the RED data set (see Figure 5A) reached its maximum values on 28 August 2001. That day was very exceptional. For the whole experiment, more than $95 \%$ of the observations were made while winds were coming from the West, i.e., from a wind sector $60^{\circ}-120^{\circ}$. During that day, as the air mass backward trajectories indicated, the air masses originated over the Pacific Ocean and have passed over part of the Hawaiian archipelago. It is also interesting to mention that during that day a storm event took place. Knowing all these details it can be understood the presence of the fine mode in the first eigenvector for RED data (Figure 4B). 
A)

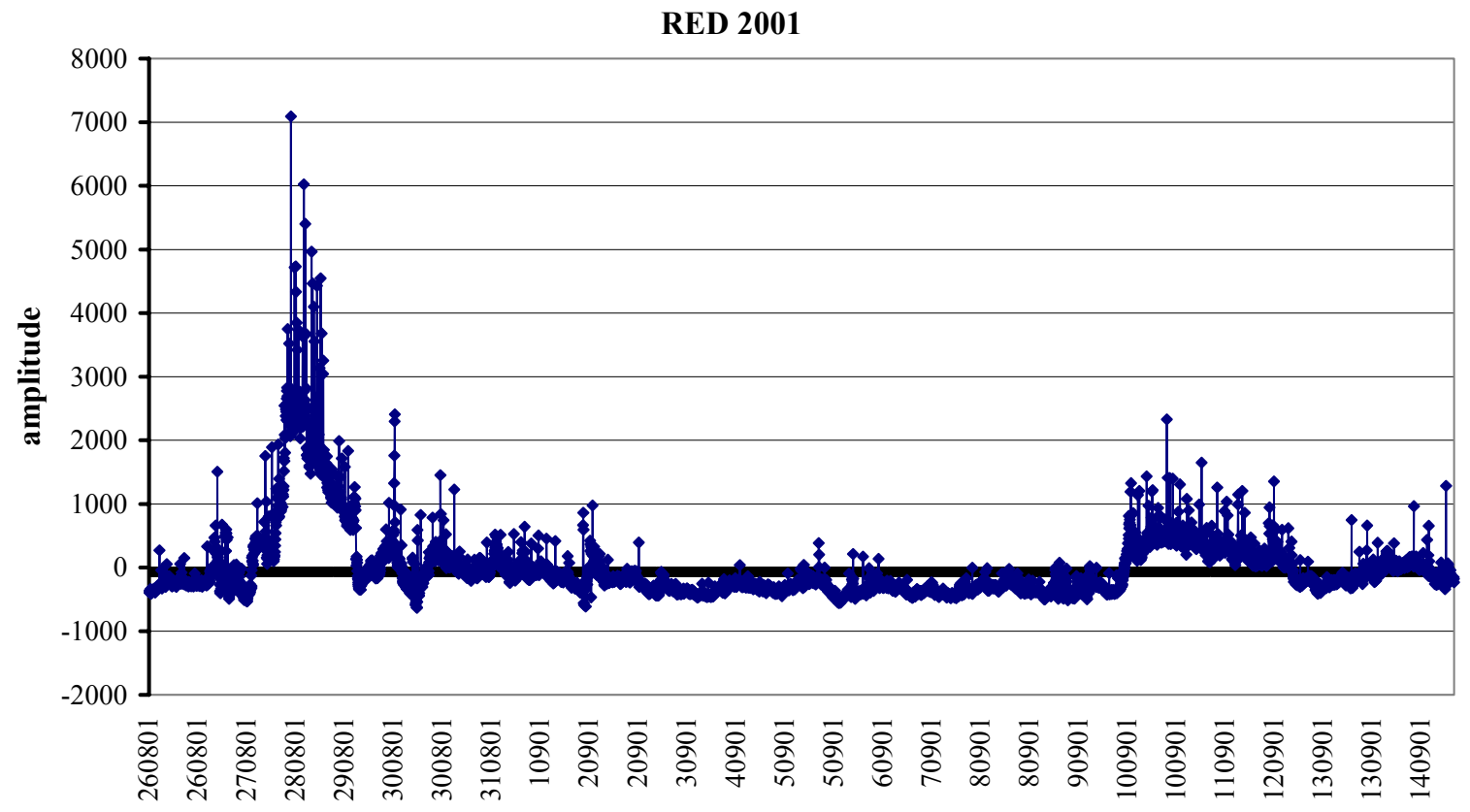

B)

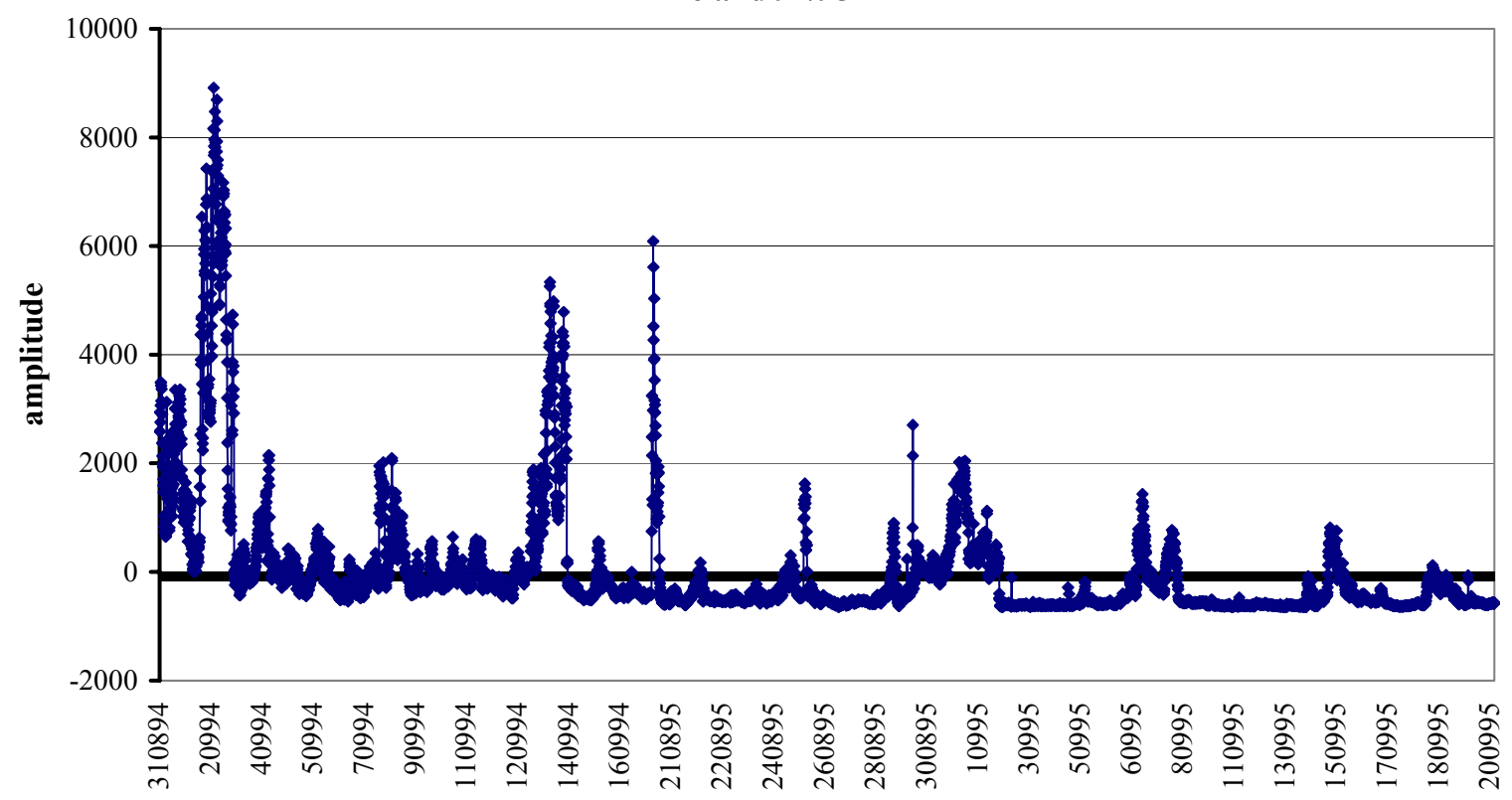

Fig.5. The amplitude function for the RED (A) and Inisheer (B) data sets. 
The high values of the amplitude function for the Inisheer data set (see Figure 5B) indicate for the periods when the continental influences were observed.

Eq.10 and 11 can be written in a different way:

$$
\mathrm{n}_{\mathrm{i}}(\mathrm{r})=h_{1}(\mathrm{r}) \beta^{\prime}{ }_{\mathrm{i} 1}+\mathrm{n}_{\min }(\mathrm{r}) \quad i=1, \ldots, N
$$

where the positive fluctuations $\beta{ }^{\prime}{ }_{11}$ are defined as:

$$
\beta^{\prime}{ }_{i 1}=\beta_{i 1}-\beta_{\min }
$$

Although the form of equation 12 is equivalent to that of eq.10, the physical interpretation is different. In eq. $10 \mathrm{a}$ temporary deviation from the mean size distribution $(<\mathrm{n}(\mathrm{r})>)$ is given by the product of the amplitude function $\left(\beta_{\mathrm{i} 1}\right)$ and the eigenvector $\left(h_{1}(\mathrm{r})\right)$. The amplitudes can be positive or negative. The positive contribution of $h_{1}(\mathrm{r})$ can be interpreted as a "production", the negative one as a "deposition" with respect to the mean distribution. In eq.12 the aerosol size distribution $\mathrm{n}_{\mathrm{i}}(\mathrm{r})$ is a superposition of a background distribution (the minimum size distribution $\mathrm{n}_{\min }(\mathrm{r})$ ) and the positive contribution of $h_{1}(\mathrm{r})$.

\subsection{The background aerosols}

The size distribution for the background aerosols can be obtained using the information about the minimum amplitude value. In case of the RED experiment the amplitude values, very close to the minimum one, were observed quite often e.g. during the whole period from $2^{\text {nd }}$ to $10^{\text {th }}$ of September. In case of the Inisheer experiment the periods corresponding to the very low amplitude values were very short.

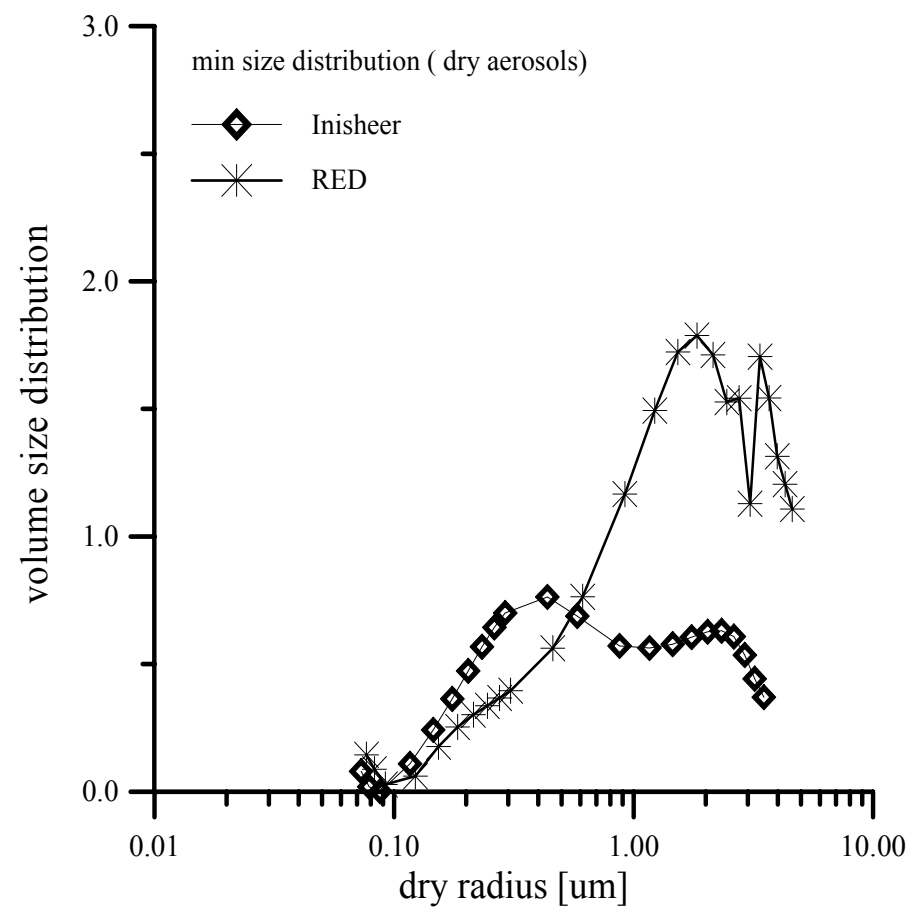

Fig. 6. The volume size distribution for the dry background aerosols, for the Inisheer and RED experiments. 
Figure 6 presents the volume size distribution obtained for the dry background aerosols i.e. described by the min number size distribution $\mathrm{n}_{\min }(\mathrm{r})$. For the RED data the volume size distribution is represented mainly by oceanic particles (coarse mode). For the measurements characterized by the high values of amplitude function the profile of the background aerosols will change and will look more like the first eigenvector (see Fig.7). For Inisheer data the background aerosols are described by two modes: fine and coarse. Adding the high contribution of fine particles will change this profile (Fig.7) to almost one mode distribution.

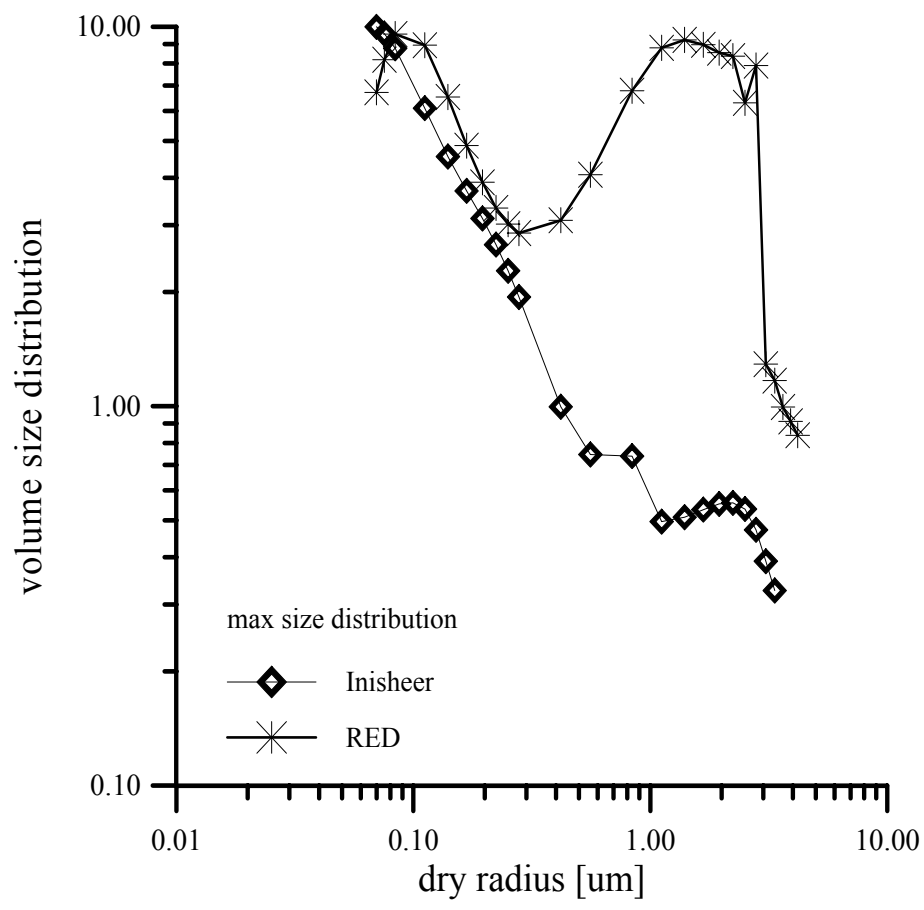

Fig.7. The volume size distribution obtained for the max number size distribution, for the Inisheer and RED experiments. The results are presented for the dry aerosols.

\subsection{Extinction}

The relation between the aerosol size distribution and the extinction coefficient $C(\lambda)$ can be described by the relation:

$$
C(\lambda)=\pi \int_{r 1}^{r 2} r^{2} \mathrm{Q}_{\mathrm{ex}} \mathrm{n}(\mathrm{r}) \mathrm{dr}
$$

where $\lambda$ is a wavelength, $r$ is a radius and $Q_{e x}$ is the extinction efficiency factor, being a function of the complex index of refraction. Taking into account eq 10 the extinction formula can be presented as;

$$
\mathrm{C}(\lambda)=<\mathrm{C}(\lambda)>+\beta_{\mathrm{i} 1} \mathrm{C}(\lambda)^{*}
$$

and

$$
\mathrm{C}(\lambda)_{\max / \min }=<\mathrm{C}(\lambda)>+\beta_{\max / \min } \mathrm{C}(\lambda)^{*}
$$


where $<\mathrm{C}(\lambda)>$ is the extinction calculated for the mean size distribution and $\mathrm{C}(\lambda)^{*}$ the extinction calculated for the first eigenvector. Eq 15 demonstrates that the temporal variation of the extinction can be expressed by the amplitudes. The extinction values calculated for two extreme aerosol size distributions i.e. $\mathrm{n}_{\max / \min }$ (see Eq.16), determine the range of its variability.

\section{DISCUSSION}

The EOF method can characterize the behavior of the aerosol distribution towards varying environmental conditions. In this paper it is shown that in a simple manner the differences between coastal and oceanic aerosol types can be described using one equation. The method also quickly provides insight in the variability of the concentration and extinction in the data set The EOF method could reveal the difference between oceanic and coastal data

The EOF method is potentially important to the further ANAM development, since it provides a mathematical tool to study the behaviour of the complete aerosol size distribution as function of meteorological parameters. The regression analysis that is used traditionally at TNO focuses on a single radius only, and requires that "characteristic" radii are chosen (continental vs marine diameter, etc). It is arguable whether a single diameter can serve as a probe for a specific type of aerosol with associated behaviour as function of meteorological parameters and fetch.

In principle, the EOF method yields a complete model for the aerosol size distribution - in this respect it replaces ANAM. However, it is not anticipated that such an integral approach would replace the present model with dedicated modes. On the other hand, the EOF analysis provides insight as to how these dedicated modes should vary with the environmental conditions and thus provides an interesting complement to the regression methods traditionally used at TNO.

\section{ACKNOWLEDGEMENTS}

This work has been sponsored by the Office of Naval Research contract (N68171-05-P-0147). The authors acknowledge the instrumental efforts of Gerrit de Leeuw in obtaining the aerosol database. The enthusiastic participation of Gerrit de Leeuw, Gerard Kunz, Marcel Moerman and Leo Cohen in the PMS measurements is gratefully acknowledged.

\section{REFERENCES}

1. E. N. Lorenz, "Empirical orthogonal function and statistical weather, Statistical Forecasting Project," Sci. Rep., 1, Dept. of Meteorol., Mass. Inst. of Technol. Cambridge, 49 pp. (1954).

2. A. Jankowski, "The application of EOF in the analysis of the variability of water temperature, salinity and density in selected regions of the Norwegian Sea," Oceanologia 35, 27-60 (1994).

3. P. B. Nielsen, "On empirical orthogonal functions (EOF) and their use for analysis of the Baltic Sea level", Rep. 40, Inst. Fys. Oceanogr., Københavns Univ., Copenhagen, pp.37 (1979).

4. J. Kusmierczyk-Michulec and M. Darecki, "The aerosol optical thickness over the Baltic Sea", Oceanologia 38(4), 423-435 (1996).

5. J. Kusmierczyk-Michulec, O. Krueger and R. Marks, "Aerosol influence on the sea-viewing wide-field-of-view sensor bands: Extinction measurements in a marine summer atmosphere over the Baltic Sea", J. Geophys. Res., 104(D12), 14293-14307 (1999).

6. J. Kusmierczyk-Michulec, and R. Marks, "Modelling of the aerosol size distribution over the Baltic Sea", Oceanologica Acta, 20(6), 881-884 (1997).

7. S.G. Gathman, "Optical properties of the marine aerosol as predicted by the Navy Aerosol Model", Opt. Eng. 22, 57-62, (1983).

8. H.E. Gerber, "Relative humidity parameterization of the Navy Aerosol Model (NAM)", NRL report 8956, NRL Washington DC, 1985. 
9. S.G. Gathman, "A preliminary description of NOVAM, the Navy Oceanic Vertical Aerosol Model”, NRL report 9200, NRL Washinton DC, 1989.

10. F.X. Kneizys, L.W. Abreu, G.P. Anderson, J.H. Chetwynd, E.P. Shettle, A. Berk, L.S. Bernstein, D.C. Robertson, P. Acharya, L.S. Rothman, J.E.A. Selby, W.O. Gallery and S.A. Clough, "The Modtran 2/3 report and Lowtran 7 model", Philips Laboratory PL/GPOS, Hanscom AFB, MA, (1996).

11. A.M.J. van Eijk, "Improvements in the Advanced Navy Aeorosol Model (ANAM)", SPIE conference 6303 (2006).

12. A.M.J. van Eijk and G. DeLeeuw, "Modeling aerosol extinction in a coastal environment", SPIE Proceedings 1688, 28-36, (1992).

13. J. Piazzola A.M.J. van Eijk and G. DeLeeuw, "An extension of the Navy Aerosol Model to coastal areas". Opt.Eng. 39, 1620-1631, (2000).

14. J. Piazzola, F. Bouchara, G. DeLeeuw and A.M.J. van Eijk, "Development of the Mediterranean extinction code (MEDEX)." Optical Engineering, 42, 912-924, (2003)

15. R. W. Preisendorfer, Principal component analysis in meteorology and oceanography, Elsevier, AmsterdamOxford-New York-Tokyo, 425 pp. (1988).

16. A. Ralston, Introduction to numerical analysis, Pol. Wydaw. Nauk., Warszawa, 589 pp. (1975). 